\title{
A method for determining ice-thickness change at remote locations using GPS
}

\author{
Christina L. Hulbe and Ian M. Whilians \\ Byd Polar Research Center and Department of Geological Sciences, The Ohio State University, Columbus, OH 43210, U.S.A.
}

\begin{abstract}
Ice-thickness changes at remote locations on ice sheets can be determined by means of precise Global Positioning System (GPS) surveys with interferometric solutions. Remote sites are precisely surveycd relative to GPS receivers on rock. Repeat observations of the position of a remote site provide its vertical velocity. The difference between this velocity and accumulation rate is an indicator of change in ice-sheet thickness. Allowance must be made for the movement of survey markers due to firn compaction and down-slope ice motion. To allow for firn compaction, very long polcs arc placed to a sufficient depth in the firn that the densification rate can be considered stcady. This assumption may be tested by measurements with poles set to different depths. An analysis of errors in pilot studies indicates that the limit to precision is the determination of accumulation rate.
\end{abstract}

\section{INTRODUCTION}

A method for measuring the mass balance for a small region of an ice sheet is needed. The usual method is to compare snow input with horizontal output (e.g. Kostecka and Whillans, 1988; Whillans and Bindschadler, 1988; Bindschadler and others, 1993) but arcas on the order of $10^{4} \mathrm{~km}^{2}$ must be considered so that uncertainties associated with the depth variation in velocity or the boundaries of the catchment arca do not dominate the calculation. New methods use repeat satellite-radar altimetry to observe surface-elevation change (Zwally, 1984; Wingham and others, 1993). The potential problems with this method are associated with signal penetration into the firn, ambiguity duc to beam width and off-pointing, and uncertainties in satellite orbits and track positioning. Repeat laser altimetry from aircraft is another promising possibility. Both new methods have great merit in the ability to obtain locally specific changes over large regions. However, these techniques are limited in that thcy cannot distinguish between time changes in ice mass and changing firn density. Firn density may be expected to change most importantly at shallow depths, due, for example, to secular changes in mass loss by vapor transport, or espccially warm or cool summers affecting densification. Also, it is well established that accumulation rate varies significantly over short time-scales (Mosley-l'hompson, 1980; Jouzel and others, 1983), such as the several years between altimetric observations. Because they are linked strictly to the surfacc, remotc obscrvations are especially sensitive to such changes. A locally applicable method is needed that is less affected by rapid, short-duration variations and that applies to long time-scales. Such measurements are valuable in themselves and would also provide calibration, or fiducial sites, for altimetric techniques.

The method proposed here, using the Global Positioning System (GPS), offers a rapid and precise local measure of icc-thickncss change. The technique uses post-processing of simultaneous satellite tracking from receivers at remote sites on the ice sheet and at reference sites on rock to provide accurate horizontal and vertical positions for the remote sites. Markers are planted in the firn or ice at the remote site. Re-occupation at a later time to observe change in position of the marker yiclds a vertical velocity related to firn accumulation and rate of ice-thickness change. The extent to which the vertical velocity may not be compensated by the accumulation rate is a measurc of icc-thickness imbalance.

\section{THEORY}

An ice sheet might not be in steady state for two reasons. First, there may have been a change in the balance between surface-accumulation rate and ice flow and basal melting/freezing. 'This results in a net mass imbalance in which the downward motion of the icc is not being exactly matched by new addition of ice at the top. This difference, the net change in icc thickness, $\dot{H}$, is the objective of the work here. Secondiy, there may have been a change in firn properties or accumulation rate that affects the rate of firn settling. We seek to avoid this complication by placing the markers as deeply as possible in the firn so as to be less affected by short-term flucluations in firn temperature and accumulation rate. Ideally, the markers should be set in solid ice but depths of some tens of meters may be all that is feasible.

As firn accumulates, it settles and thereby densifies. 
Each particle is continuously being displaced downward. If the accumulation rate, $b$, is constant, the firn moves downward at the rate: $-\dot{b} / \rho(z)$, where density, $\rho$, increases with depth, $z$. This relation is known as Sorge's law (Paterson, 1981, p. 16). The negative sign indicates downward motion.

A marker in the firn moves downward with this firn settling and is also affected by any rate of change of thickness of the icc beneath. This quantity, the long-term rate of thickness change, $\dot{H}$, is added to the settling velocity to obtain the vertical velocity of the marker, $w$ :

$$
w=\frac{\dot{b}}{\rho(z)}+\dot{H} .
$$

No separate account of basal mclting or basal freezing need be taken. Any vertical velocity due to crustal motion has been neglected. Equation (1) is applied to measured velocities of markers planted at specific depths (and densities and solved to compute a rate of ice-thickness change, $\dot{H}$, from each marker. If markers at several depths are used, a linear relationship is expected between $w$ and $1 / \rho$ if Sorge's law applies.

A part of the vertical motion of the marker is due to down-slope ice flow. If the surface slope is constant with time, the effect of down-slope flow is removed by considering not quite the vertical velocity of markers but the surface-perpendicular component of velocity. For most ice sheets, slopes are on the order of 0.002 , so the directions of vertical and surfacc-perpendicular are very similar.

\section{FIELD METHOD}

Data collection has three elements:

1. Long-distance tie between remote site and stable GPS stations.

2. Emplacement of deep vertical velocity markers and their survey conncction to the long-distance tie.

3. Collection of ancillary data:
a. Surface slope.
b. Profile of firn density.
c. Local accumulation rate.

Its application at Amundsen-Scott South Pole Station and Byrd Station is discussed here. Neither site has a completc suite of measurements. At South Pole, a new experiment was established in January 1993. Several markers werc placed and surveyed once, surface slope was measured and firn-density profiles were recorded for each marker hole. The markers will be rc-surveyed for rate of thickness-change calculations after several years. All GPS and density-profile discussions refer to this site. The firnsettling evaluation is drawn from old survcys near Byrd Station (Gow, 1968; Whillans, 1991). There is no survey tie to a fixed location for the Byrd Station data.

\section{Long-distance tie to South Pole}

GPS data are continually recorded by a receiver at Amundsen-Scott South Pole Station and by another, on rock, at McMurdo Station on Ross Island. The separation distance is about $1300 \mathrm{~km}$. Data are collected using geodetic quality receivers, sampling at a $30 \mathrm{~s}$ interval. Both L1 and L2 GPS frequencies are recorded so that ionospheric corrections can be made. Calculations for such long-distance ties require $24 \mathrm{~h}$ or longer data sets, precise orbits and orbit-relaxation techniques. At present, solutions of long basc lines between stations on rock and ice are not complete. However, calculations for positions of receivers on rock are accurate to $0.01 \mathrm{~m}$ (personal communication from P.J. Morgan, University of Canberra, 1993). It is possible that difficulties in accounting for the motion of ice during the GPS observations may degrade the results to about $0.05 \mathrm{~m}$.

\section{Deep markers at South Pole}

The vertical motion markers are distant enough from long-standing camps that artificial effects due to snowdrifting or compaction are avoided. A minimum distance is $2-3 \mathrm{~km}$, the response distance of katabatic wind to a disturbance (Whillans, 1975). The present site (Fig. 1) is about $7 \mathrm{~km}$ along $130^{\circ} \mathrm{E}$ from the station structures. The prevailing wind is from about $20^{\circ} \mathrm{E}$. The site is too small to present a drifting problem of its own and was constructed with as little disturbance to the area as possible.

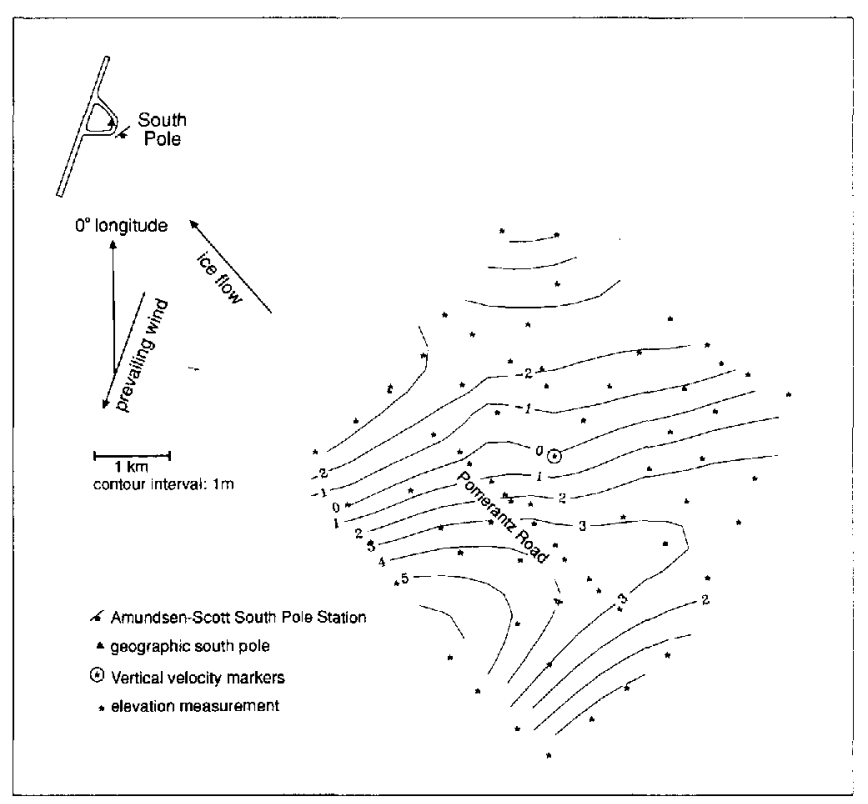

Fig. 1. Location of monitoring site installed near Soulh Pole. Deep markers are placed in a ring at the circled asterisk. Other asterisks indicate slations of the GPS surface-slope survey. Contours (in $m$ ) are of surface height relative to the marker site.

The vertical motion markers are long poles, spaced several meters apart, planted at depths of $4,6,8,10,12$, 14,16 and $20 \mathrm{~m}$ within the firn during January 1993. Observations at multiple depths (and densities) are required to test the validity of Sorge's law in Equation (1). For each marker, a hole was hand-augered to the desired depth. Long poles were constructed by connecting sections of $19 \mathrm{~mm}$ diameter hollow-steel conduit. A stccl 
can $0.1 \mathrm{~m}$ diameter $)$ filled with slush was frozen on to the bottom of each long pole as a footing to prevent penetration below the bottom of the hole. In effect, it is the motion of the steel can that is being monitored. A plywood cap is placed around each pole and over the hole, and buried with snow to prevent filling by windblown snow. Thus, the hole remains open and the pole is not gripped by firn at any depth other than the hole bottom. This concern is also assuagcd by the use of steel conduit with nearly flush connectors whose smooth surface is not easily gripped by firn. The poles flex slightly as constrained by the holc walls. The amount of flexure does not change with time. The elevations of the pole tops are measured over a span of years.

A static GPS technique is used to make the connection between the marker site and the long-distance tracker at Amundsen-Scott South Pole Station. Dual-frequency phase observations of an hour or more are made with an antenna placed directly on top of one of the marker poles. Post-processing produces a rclative position accurate to $0.01 \mathrm{~m}$. The positions of the other markers are surveyed relative to the first, using the stop-and-go kinematic GPS tcchnique (Hulbe and Whillans, 1993) and by optical levelling. For these GPS surveys, a fixed reference receiver is placed on the marker pole which has been surveyed relative to the South Pole receiver. With the fixed receiver continually tracking phase of the GPS signals, a second antenna, also continually tracking, is placed, in turn, on each of the other pole tops. Ten or more epochs of $\bar{j} \mathrm{~s}$ interval data are collected on each marker. Differcntial post-processing determines the positions of the pole tops with respect to the marker used as the fixed location. Becausc only the polc tops are used for the survey, antenna heights are zero. Thus, problems related to changing surface conditions and setting of the antenna are avoided. Similar kinematic GPS surveys elsewhere in Antarctica (Hulbe and Whillans, 1993) yield accuracies of $0.005 \mathrm{~m} \mathrm{~km}^{-1}$ or better for horizontal and vertical components. The optical levelling for the example used here from near Byrd Station is internally consistent to $0.002 \mathrm{~m}$. The relationships of survey steps, from a permanent site on rock to vertical motion markers, are skctched in Figure 2.

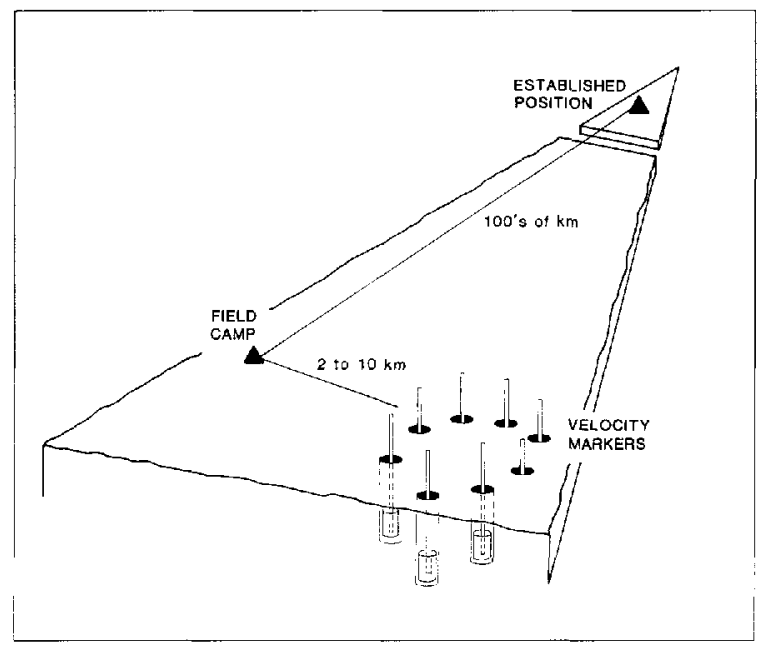

Fig. 2. The positions of fim markers are linked to a field camp and to a stable site.

\section{Ancillary data}

\section{Surface slope at South Pole}

The stop-and-go kinematic GPS technique is used to determine surface slope. A receiver was left tracking at the marker site and a vehicle carrying a second GPS antenna drove a $4 \mathrm{~km}$ by $4 \mathrm{~km}$ grid around the site, stopping about every $500 \mathrm{~m}$. Five ten epochs of $5 \mathrm{~s}$ interval data were collected at each stop for a precise position calculation. The sites of such stops are shown in Figure 1. The area surveyed is large enough to represent accurately the local surface and enough points are observed to avoid biasing by local surface micro-relief.

At this site, the slope is $2.5 \mathrm{~m} / 1000 \mathrm{~m}$ in the flow direction known to be $8.5 \mathrm{~m} \mathrm{a}^{-1}, 40^{\circ} \mathrm{W}$ at the station (United States Geological Survey, 1976)). Slope calculations along repeated grid lines agree to within $10 \%$, leading to our estimate of $0.25 \times 10^{-3}$ for the slope error.

The local surface topography may change between observation epochs. For example, surface slope may change or topographic features may migrate through the surveyed area. Such phenomena may indicate nonstcady ice flow. This possibility should be assessed by repeating the local surface topography survey for each cpoch.

\section{Firn-density profile at Soulh Pole}

Firn density at the depth of each marker is needed. This is obtained from cores retrieved when the holes are drilled.

Errors in density are mainly due to uncertainties in core diameter, which affect each density by about $2 \%$. Uncertainties and the possibility of horizontal variation in density are evaluated from the reproducibility of density profiles. The standard error is $1 \%$ at $6 \mathrm{~m}$ depth and $1.6 \%$ at $10 \mathrm{~m}$ depth for the cores at the South Pole site, which are within $20 \mathrm{~m}$ of one another. Such variability is within measurement uncertainty. A further estimate of density precision is obtained from the scatter of values in the test of Equation (1), as discussed in relation to Figure 3. The correlation coefficient for the regression suggests a density uncertainty of $3 \%$.

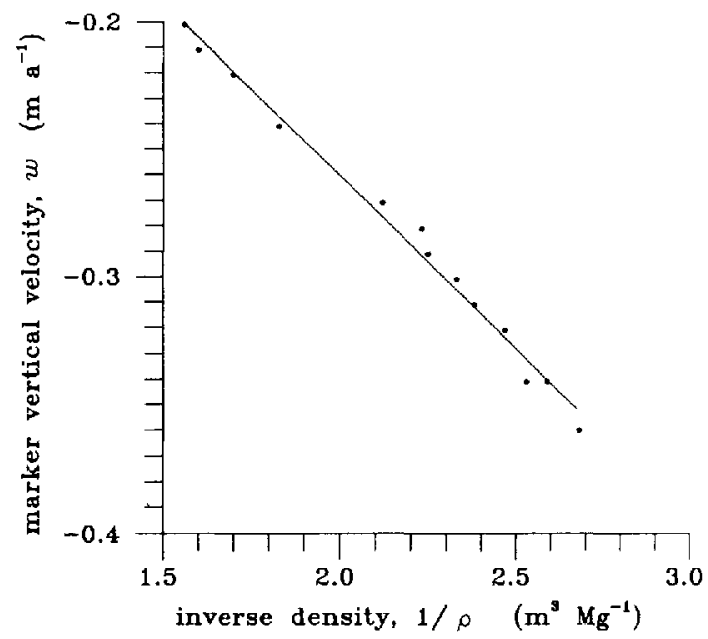

Fig. 3. Vertical velocity of marker versus inverse density at marker depth. The data are from deep anchors at several locations near Byrd Station. The observation interval is about 2 years. 
Uncertain core break and lost sections of core cause some uncertainty in the depths of density values. The depth unccrtainty is calculated following Whillans and Bolzan (1988) and is about $0.015 \mathrm{~m}$. This is relatively unimportant.

\section{Accumulation rate}

The accumulation rate is best obtained independently, at the marker site, using stratigraphic methods, such as the detection of horizons of gross $\beta$ activity or dust layers in ice cores. Whillans and Bindschadler (1988) found that the largest error sources are with the densities of samples between the dated horizons, which affect accumulation rates by about $2 \%$ (Table 1 , note 11 ), and spatial irregularities in the strata due to sastrugi, which can affect accumulation rate by scveral per cent (Whillans 1975 calculated about $0.01 \mathrm{~m}$ a ${ }^{1}$ along the Byrd Station Strain Network). Note that density error affects the calculation in two places, first, at the marker depth (see above) and here, where the depth-integrated density between dated strata is needed.

Spatial variability in accumulation ratc is important.

Table 1. Uncertainties in mass-balance calculation

Observation

Measurement

Standard error

Standard error in Equation (2)

Surface-perpendicular velocity (w)
Tie from rock to camp

Tie from camp to polc top

Vertical position 1 ;

Vertical position

Vertical position of marker ${ }^{3}$ (combination of above)

Regional elevation survey

Horizontal velocity

Surface perpendicular velocity correction

Surface slope 4

Horizontal position

Velocity due to accumulation $(\dot{b} / \rho)$

Density, $\rho$, at depth of marker

Accumulation rate, $\dot{b}$
Dimensions and mass (7)
By firn scttling 9
Or by core stratigraphy

$0.050 \mathrm{~m}$

$0.010 \mathrm{~m}$

$0.051 \mathrm{~m}$ each observation
$0.250 \times 10^{3}$
$0.010 \mathrm{~m}$
$0.002 \mathrm{~m} \mathrm{a}^{-1 / 6)}$
Error in $\dot{H}$

For 5 years between obscrvations

\section{Notes}

1) Vertical position from a static calculation between a GPS receiver on the ice sheet (at Amundsen Scott South Pole Station) and an established GPS receiver (McMurdo Station, on rock).

(2) Vertical position of a vertical motion marker, made with a GPS tie relative to the ficld camp receiver at Amundsen-Scott South Pole Station).

(3) The root of summed squares of the position errors, 1 and (2).

i4) From a kinematic GPS survey around the marker site.

(5) From the same survey opcration described in notes 1 ) and (2).

6. The surface-perpendicular velority is the dot product between the unit vector normal to the snow surface, $\hat{\mathbf{n}}$, and ice velocity, $u$. That is: $w=u \cdot \hat{\mathbf{n}}=u_{r} n_{x}+u_{y} n_{y}+u_{z} n_{*}$ in which the subscripts identify the vector components. This is simplified by considering only the vertical, $z$, and along-flow, $x$, components. Let $\alpha$ represent slope angle. Then $w=u_{x} \sin \alpha+u_{z} \cos \alpha$. Error propagation using this equation links standard errors in each quantity. The effect of error in slope is $\left(u_{r} \cos \alpha+u_{z} \sin \alpha\right) \sigma_{\mathrm{x}}$ and considering that $\alpha \ll 1$, this becomes $\left(u_{x}+a u_{z}\right) \sigma_{x}$. This is evaluated, assuming a 5 year observation interval, using estimates appropriate for South Pole $u_{x} \approx 8.5 \mathrm{ma}$ '. $\alpha \approx 2.5 \times 10^{3}, u_{z} \approx 0.1 \mathrm{ma}^{1}$ and $\sigma_{x}=2 \times 10^{4}$, to provide the value in the table.

(7) Density is calculated using $\rho=4 M / L \pi D^{2}$ where $M$ represents sample mass, $L$ is sample length and $D$ is sample diameter. Diameter uncertainty is the most limiting factor Whillans and Bindschadler, 1988). Neglecting other contributions, the error in density is $\sigma_{p}=$ $\left(8 M / L \pi D^{3}\right) \sigma_{D}=(2 \rho / D) \sigma_{D}$ where $\sigma_{D}$ represents the ceror in diameter measurement. Representative values are $\rho=0.5 \mathrm{Mg} \mathrm{m}^{3}, D=0.076 \mathrm{~m}$, $\sigma_{D}=0.001 \mathrm{~m}$. By this error propagation, $\sigma_{p}$ is $0.013 \mathrm{Mgm}{ }^{3}$.

An independent estimate comes from the standard deviation of the regression fit in Figure 2. That is $3 \%$ of $0.015 \mathrm{Mg} \mathrm{m}^{3}$. This slightly more pessimistic valuc is reported in Table 1.

(8) From Equation (2), the effect is: $\left(b / \rho^{2}\right) \sigma_{p}$. The value in Table 1 is calculated with $\dot{b}=0.14 \mathrm{Mgm}{ }^{2}$ a $^{1}$ typical for Byrd Station $)$

(9) Error obtained from the statistics of the regression in ligure 2.
(10) From Equation (2), the effect is $\sigma_{i} / \rho$.

11) There are four important sources of error in accumulation rate determined by core stratigraphy. Two stem from data collection and wo from natural phenomena.

The lirst two uncertainties in accumulation rate are due to uncertainties in core-diameter measurement. The accumulation rate from a single core is calculated from $\dot{b}=1 / T \sum 4 M / \pi D^{2}$ in which $T$ represents the time interval between dated strata. 'I he sum is taken over $N$ samples. The mass and diameter of each sample along the core are represented by $M$ and $D$, respectively. Accuracy is almost entirely limited by the diameter in which there may be 1 random and 2 sustrmatic crrors. Random measurcment crrors in diameter, $\sigma_{D \text { rmmltmu, affect the }}$ accurnulation rate according to $\sigma_{\text {hrandm }}=(2 \sqrt{N} \rho / T D) \sigma_{D \text { random. }}$. A systematic bias in diameter, $\sigma_{D \text { mitematic, affects arcumulation rate }}$ according to $\sigma_{i \text { systematic }}=(2 b / D) \sigma_{D \text { sutematic }}$.

Measurement errors are estimated for the case of accumulation rate determined by the detection of $\beta$ fall-out horizons, a common method. A corc is augered to a depth of $15-20 \mathrm{~m}$ to find the stratum containing the start of radioactive fall-out in 1955. Typical values from such an analysis are $N=40, \quad T=40$ a, $D=0.076 \mathrm{~m}, \quad \rho=0.5 \mathrm{Mgm}^{3}, \ddot{b}=$ $0.14 \mathrm{Mgm}{ }^{2} \mathrm{a}^{1}, \sigma_{D \text { random }}-0.001 \mathrm{~m}$ and $\sigma_{D \text { sistematic }}=0.001 \mathrm{~m}$. This leads $10 \sigma_{b \text { random }}=0.002 \mathrm{Mgm}^{2} \mathrm{a}^{1}$ and $\sigma_{b_{\text {sutentatic }}}=0.004 \mathrm{Mg} \mathrm{m}^{2} \mathrm{a}^{1}$.

A third uncertainty arises because depositional strata are horizontally variable on the $10 \mathrm{~m}$ scale due to sastrugi. 'I hus, there is a sampling error. Letting $\sigma_{\mathrm{s}}$ represent sastrugi roughness (for simplicity, taken to be the same for both the upper and lower strata), the associated standard error in accumulation rate is $\sigma_{i}$ sistrugi $=(\sqrt{2} / T) \sigma_{*}$. Using a valuc of $0.02 \mathrm{~m}$ for $\sigma_{\mathrm{s}}$ as reported for near Byrd Station Whillans. 1978, the sastrugi eflect is $0.0006 \mathrm{Mg} \mathrm{m}^{2} \mathrm{a}^{\mathrm{l}}$.

The fourh uncertainty arises from short-term variability in accumulation ratc, as discussed in the text under "long-term significance". 'l'he standard error at South Pole due to this is $0.0038 \mathrm{Mgm}^{2}$ "a ',

Combining all four suturces of error, the net standard cror is $0.006 \mathrm{Mgm}^{2} \mathrm{a}^{1}$.

(12) The solution of Equation (2). 
Jouzel and others (1983) compared independent accumulation-rate determinations near South Polc. They found a rariability of $30-40 \%$ between authors. All these authors assumed that spatial variations in density are unimportant and, indeed, the variations seem too large to be due to density. Whillans (1978) found accumulation rates along the $168 \mathrm{~km}$ long Byrd Station Strain Network to rary by $14-40 \%$ over distances of about $10 \mathrm{~km}$. These works point to the importance of obtaining the accumulation rate from cores taken at the markcr site.

The long-term accumulation rate may also be obtained from firn settling as a result of the solution of Equation (1) as discussed below.

\section{Firn settling}

An application near Byrd Station is illustrated in Figure 3 (from Whillans, 1991). The markers were planted at depths ranging $1025 \mathrm{~m}$ and surveyed with oplical techniques. Densities are obtained from Gow (1968). The surveying was done long ago and so there is no connection to a fixed location. Thus, there is an unknown constant error in the vertical velocity, $w$, and the data cannot be used to compute mass balance. However, they can be used to demonstrate a test of the model of firn scttling. In Figure 3, measured vertical velocities are plotted against inverse density at marker depth. If Sorge's law applies, Equation (1) predicts a straight line. This scems to be the case, which supports the assumption that firn densification is steady. That is, past changes in firn temperature, or in the rate of loading by new snow, or in vapor transfer within the firn pack are not important. Should the relation not be linear, there would be some complicating process, which must be identified in order to determine which marker velocities are most meaningful.

A linear regression on the data of Figure 1 yields an accumulation rate (the slope of the best-fit line) of $0.137 \mathrm{Mg} \mathrm{m}^{2} \mathrm{a}^{1}$. The standard error on this estimate is $0.04 \mathrm{Mg} \mathrm{m}^{2} \mathrm{a}^{1}$; the scatter is taken as due to crror in density and all values are assigned equal weight. This error is larger than the error associated with accumulation rate obtained stratigraphically. Therefore, it seems prudent to obtain the accumulation rate from stratigraphic studies on an ice core taken at the measurement site, rather than rely on this use of Sorge's law.

The accumulation rate derived from the regression is within the range of other estimates from nearby sites, A rate of $0.140 \mathrm{Mg} \mathrm{m}^{2} \mathrm{a}^{1}$ is obtained for the interval 1925 60 from pit and core work at Old Byrd Station Gow, 1961). A rate of $0.144 \mathrm{Mg} \mathrm{m}^{2} \mathrm{a}^{2}$ is obtained for the interval 1930-61 from pit and core work at New Byrd Station Kocrncr, 1964). And, a rate of $0.104 \mathrm{Mg} \mathrm{m}^{-2} \mathrm{a}^{-1}$ is obtained for the interval 1925-63 from a $10 \mathrm{~m}$ pit at New Byrd Station Cameron, 1971). This agreement supports the general soundness of the method and Equation (1).

\section{Long-term significance}

The rate of snow accumulation varies with time, yet the motion of the glacier is linked to the response time of the glacier, which is thousands of years. An accumulationrate record spanning thousands of years is preferred.
The lime variability in accumulation rate is estimated from a long time series. There are 911 yearly accumulation-rate values from a long core collected at South Pole (Mosley-Thompson, 1980, table 13). The values come from the spacing of dust layers and a density profile of uncertain accuracy. The standard deviation of 40 year averages is $0.0038 \mathrm{Mg} \mathrm{m}^{2} \mathrm{a}^{-1}$ (40 years is comparable to the time-scale applicable to accumulation rate from gross $\beta$ activity. 'This standard deviation is a measure of the confidence with which accumulation rate from a single short core can be used to estimate long-term accumulation rate.

This standard error is similar to the accumulation-rate calculation error $\left(0.0045 \mathrm{Mgm}^{2} \mathrm{a}^{1}\right.$; Table 1 , note 11$)$. For South Pole, the assumption that accumulation rate is constant, as required by Sorge's law, seems to be about as limiting as errors in field measurements.

\section{Error analysis}

The ratc of ice-thickness change, $\dot{H}$, is obtained by solution of Equation (1). The standard error for $\dot{H}$ is given by:

$$
\sigma_{\dot{H}}=\sqrt{\frac{2 \sigma_{z}^{2}}{\Delta t^{2}}+\left(\frac{\sigma_{\dot{b}}}{\rho}\right)^{2}+\left(\frac{\dot{b}}{\rho^{2}} \sigma_{\rho}\right)^{2}}
$$

where $2 \sigma_{z}{ }^{2}$ represents the combined vertical positioning error for surveys at two different epochs, $\sigma_{b}$ represents the crror in accumulation rate, $\sigma_{p}$ represents the error in density at marker depth and $\Delta t$ represents the time interval between surveys. Fach contribution is addressed in Table 1.

The largest uncertainty in the calculation is due to difficulties in obtaining a precise value for the long-term accumulation rate, $\sigma_{\dot{b}}$. In that, the problems are with obtaining good core diameters for density determination and short-term variability in accumulation rate. Measurement errors can be reduced by making frequent and precise obscrvations. Collecting as long a record as possible may reduce the importance of short-term changes in accumulation rate.

The error produced by uncertainty in density at the marker depth, $\sigma_{\rho}$, is much smaller. It could be reduced by rigorous diameter measurement and by combining the observations for all markers.

The accuracy of the vertical velocity is limited by the GPS tie between the marker site and a fixed location on rock. Increasing the time between observations improves the precision. In this analysis, a 5 year interval is selected.

The errors in accounting for down-slope flow Table 6 , note 6 ) are very small. Some workers have elected to reobserve the same geographic location in order to avoid this effect. In this application, such concerns are not necessary.

\section{CONCLUSION}

The method is a practical approach to determining local rates of ice-thickness change. 'T'he installation of the firn markers, measurement of depth-density profiles, first 
survey and collection of slope data at South Pole required $6 \mathrm{~d}$. Re-surveys of the markers will require 1 or $2 \mathrm{~d}$.

As with all ice-thickness-change determinations, a difference is calculated betwcen two nearly balancing effects. In this case, the difference is essentially between the downward motion of markers and the accumulation rate. The crror on the rate of downward motion becomes smaller as the time interval between surveys lengthens; for a 5 year interval, the standard error from the surveying is expected to be about $0.014 \mathrm{~m} \mathrm{a}{ }^{1}$. For a 10 year interval, the error would be $0.007 \mathrm{~m} \mathrm{a}^{-1}$. The uncertainties in the other half of the balance cquation, the accumulation rate, are more limiting, being $0.012 \mathrm{~m} \mathrm{a}^{-1}$ for a site like Byrd Station. Together with the addition of a small crror due - to uncertainty in density at marker depth, $0.008 \mathrm{~m} \mathrm{a}^{1}$, the precision in the rate of ice-thickness change for a 5 year observation is about $0.02 \mathrm{~m} \mathrm{a}^{-1}$.

Accumulation-rate precision is limited by uncertainties in core diameter and by time variation in accumulation rate. Another potentially large error source, spatial variation, is avoided by determining the accumulation rate at the marker site. At South Polc, diameter and timevariation uncertainties are similar in magnitude. They can be reduced by making frequent and precise corediameter mcasurements and by determining the accumulation rate for as long a time interval as possible. Both aspects must be improved for a substantial improvement in the precision of the ice-thickness balance.

This method provides ice-thickness balances with long-term relevance, at least as long as the accumulation-rate rccord. The length of the accumulation-rate record is determined by the stratigraphic technique and perhaps by core-recovery capability. In the case of South Pole, the longest record is 911 years.

Methods, such as satellitc or airborne altimetry, using -observations of the snow surface yield ice-thicknessbalance values that are relevant only to the time interval between visits. Moreover, their results may be affected by secular changes in firn density and by time variations in accumulation rate. The potential for secular density change has not been cvaluated. However, it is known that net-accumulation rate varies at South Pole. Within the 911 year record from South Pole, there are 10 year intervals with mean accumulation rates that differ by as much as 33\% from the mean. A repeat snow-surfaceelevation determination over those 10 years would yicld an ice-thickness change of $0.23 \mathrm{~m}$. This could be misleading in view of the long-term constancy of netaccumulation rate (Moslcy-Thompson, 1980).

The proposed measurements would be most valuable if made at sites beneath satellite or aircraft paths. This would provide fiducial control for the altimetry, if measurements were also taken of (1) the change in snow-surface elcvation with respect to the deep markers, (2) changes in the depth-density profile from epoch to epoch, and (3) short-term accumulation-rate variation. The combination of remote altimetry and surface GPS work would bring together results with long-term significance and those with wide gcographic coverage.

\section{AGKNOWLEDGEMENTS}

J. Kohler, E. Wong, C. McDurmot and A. Ward supplied invaluable raw power (and language) for hand-augering all $90+\mathrm{m}$. Suggestions of J. Bolzan, C. Goad and two anonymous reviewers led to important improvements. This work is supported by U.S. National Science Foundation grant DPP-9020760. Ms Hulbe is supported by the U.S. Department of Energy's Fellowships for Global Change Program, administered by the Oak Ridge Institute for Science and Engineering. This is contribution Number 886 of the Byrd Polar Research Center.

\section{REFERENCES}

Bindschadler, R., P. L. Vomberger and S. Shabtaie. 1993. The detailed net mass balance of the ice plain on Ice Stream B, Antarctica: a geographic information system approach. J. Glaciol., 39(133), 471-482.

Cameron, R. I. 1971. Glaciological studies at Byrd Station, Antarctica, 1963-1965. Antart. Res. Ser., 16, 317-332

Gow, A.J. 1961. Drillhole measurements and snow studies at Byrd Station, Antarctica. CRREL (SIPRE) Tech. Rep. 78.

Gow, A.J. 1968. Deep core studies of the accumulation and densification of snow at Byrd Station and Little America V, Antarctica. CRREL Res. Rep. 197

Hulbe, C. L. and 1. M. Whillans. 1993. Stop-and-go GPS in Antarcica. Surveying and Land Information Systems, 53(2), 151-158.

Jouzel, J,, L. Merlivat, J. R. Petit and C. Lorius. 1983. Climatic information over the last century deduced from a detailed isotopic record in the South Pole snow. $\vec{f}$. Geophys. Res., 88(C4), 2693-2703.

Koerner, R. M. 1964. Firn stratigraphy studies on the Byrd Whitmore Mountains traverse, 1962-1963. Antart. Res. Ser., 2, 219-236.

Kostecka, J. M. and I. M. Whillans. 1988. Mass balance along two transects of the west side of the Greenland ice sheet. 7. Glaciol. $34(116), 31-39$.

Mosley-Thompson, E. 1980.911 ycars of microparticle deposition at the South Pole: a climatic interpretation. Ohio State Lniv. Inst. Poiar Sud. Rep. 73.

Paterson. W. S. B. 1981. The physics of glaciers. Second edition. Oxford, ctc., Pergamon Press.

United States Geological Survey. 1976. South Pole ice moves 30 feet/yr. EOS, $57(1), 21$.

Whillans, I. M. 1975. Effect of inversion winds on topographical detail and mass balance on inland ice sheets. J. Glaciol, 14 70, 85 90.

Whillans, I. M. 1978. Surface mass-balance variability near "Byrd" Station, Antarctica, and its importance to ice-core stratigraphy. 7 . Glaciol, $20(83), 301-310$.

Whillans, I. M. 1991. GPS in Antarctica. Report of a workshop: utilization of the Global Positioning System (GPS) in addressing scientific problems in Antarctica. Appendix A. Correcting GPSdetermined velocity on ice sheets for firn compaction. Ohio State University. Byrd Polar Research Center. Technical Report 91-02. A21-A25.

Whillans, I. M. and R.A. Bindschadler. 1988. Mass balance of Ice Stream B, West Antarcica. Ann. Glaciol, 11, 187-193.

Whillans, I. M. and J. F. Bolzan. 1988, $\Lambda$ method for computing shallow icc-core depths. 7. Glaciol., 34 1 18), 355-357.

Wingham, D.J., C.G. Rapley and J.G. Morely. 1993. Improved resolution ice sheet mapping with satellite radar altimeters. EOS, $\mathbf{7 4} 10,113$ and 116 .

Zwally, H.J. 1984. Observing polar-ice variability. Ann. Giaciol, 5, 191-198.

The accuracy of references in the text and in this list is the responsibility of the authors, to whom queries should be addressed. 